\title{
Integrated transcriptome and proteome analysis reveals potential mechanisms for differential abdominal fat deposition between divergently selected chicken lines
}

\section{Lijian Wang}

Northeast Agricultural University

\section{Li Leng}

Northeast Agricultural University

\section{Ran Ding}

Northeast Agricultural University

\section{Pengfei Gong}

Northeast Agricultural University

Chang Liu

Northeast Agricultural University

Ning Wang

Northeast Agricultural University

Hui Li

Northeast Agricultural University

\section{Zhi-Qiang Du}

Northeast Agricultural University

Bohan Cheng ( $\nabla$ chengbohan1027@126.com )

Northeast Agricultural University

Research article

Keywords: Fat deposition, Transcriptome, Proteome, Chicken, Adipose tissue

Posted Date: December 31st, 2020

DOI: https://doi.org/10.21203/rs.3.rs-38232/v3

License: (c) (1) This work is licensed under a Creative Commons Attribution 4.0 International License. Read Full License 
Version of Record: A version of this preprint was published at Journal of Proteomics on June 1st, 2021. See the published version at https://doi.org/10.1016/j.jprot.2021.104242. 


\section{Abstract}

Background: Genetic selection for meat production performance of broilers concomitantly causes excessive abdominal fat deposition, accompanied by several adverse effects, such as the reduction of feed conversion efficiency and reproduction performance. Our previous studies have identified important genes regulating chicken fat deposition, using the Northeast Agricultural University broiler lines divergently selected for abdominal fat content (NEAUHLF) as an animal model. However, the molecular mechanism underlying fat deposition differences between fat and lean broilers remains largely unknown.

Results: Here, we integrated the transcriptome (RNA-Seq) and quantitative proteome (isobaric tags for relative and absolute quantitation, iTRAQ) profiling analyses on abdominal fat tissues from NEAUHLF chicken lines. Differentially expressed genes $(2167$ DEGs, FDR < 0.01) and proteins (199 DEPs, FDR < 0.05) were identified in lean line compare to fat line, and down-regulated DEGs and DEPs mainly enriched in pathways related to fatty acid metabolism, fatty acid biosynthesis, and PPAR signaling; and numerous up-regulated DEGs and DEPs both enriched in lysosome pathway. Moreover, several key DEGs and DEPs involved in long-chain fatty acid uptake, in situ lipogenesis (fatty acid and cholesterol synthesis), and lipid droplets accumulation were discovered after integrated transcriptome and proteome analysis.

Conclusions: Together, our findings provided a novel insight into abdominal fat content discrepancy between the fat and lean chicken lines.

\section{Background}

The meat-type chickens (broilers) have been intensively selected for fast growth rate and better feed efficiency over the past 70 years. As the most efficient animal production system, broilers can provide cheap and nutritious animal protein for human consumption. In the meantime, with broiler's fast growth, series of problems also occur such as the decline in physiological adaptability, especially abdominal fat deposition. The excessive deposition of abdominal fats is not only unfavorable to the health of broilers, but also causing a huge economic loss to broiler producers [1]. Consequently, to solve excessive abdominal fat deposition is still an urgent task for broiler breeders all over the world.

Fat deposition in chickens is a complex quantitative trait regulated by multiple genetic and environmental factors. Previous studies showed that many lipid-related genes were differentially expressed in abdominal fat tissues for chickens fed with high-fat or normal diets, such as IGF2BP1, which was demonstrated to promote adipocyte proliferation and differentiation [2]. Since 1996, we established two broilers lines based on divergent selection on abdominal fat percentage and plasma very low-density lipoprotein (VLDL) concentration (NEAUHLF) [3], which is an ideal model for studying the molecular basis of adipose tissue growth and development. As a result, we have discovered a number of key genes underlying fat deposition through microarray [4-5] and two-dimensional gel electrophoresis technologies, such as adipocyte fatty acid binding protein (A-FABP) and Apolipoprotein A-I (Apo-Al) [6-7]. However, the 
molecular mechanism for abdominal fat deposition differences between fat and lean broiler lines remains unclear.

Recently, with the development of high-throughput sequencing technology, integration of transcriptome and proteome technologies has become an important means and routine to analyze the molecular mechanism of agricultural complex traits in farm animals [8-10]. In the present study, we examined the differences of transcriptome and quantitative proteome profiling on abdominal adipose tissues between the two broiler lines at 7 weeks of age. We identified several key DEGs and DEPs potentially involved in long-chain fatty acid uptake, in situ lipogenesis (fatty acid and cholesterol synthesis), and lipid droplets accumulation, facilitating our understanding of abdominal fat content differences between chicken lines under divergent selection.

\section{Methods}

\section{Animals and samples preparation}

Animal work was conducted according to the guidelines for the care and use of experimental animals established by the Ministry of Science and Technology of the People's Republic of China (approval number: 2006-398), and was approved by the Laboratory Animal Management Committee of Northeast Agricultural University (Harbin, China). The experimental birds were obtained from the Avian Farm of Northeast Agricultural University (Harbin, Heilongjiang, China). These broilers under divergent selection over 19 generations were employed from Northeast Agricultural University broiler lines divergently selected for high and low abdominal fat content (NEAUHLF), exhibiting a large difference in abdominal fat content as previously described [3]. In total, ten male birds (lean line, $n=5$, and fat line, $n=5$ ) at 7 weeks of age from the 19th generation of NEAUHLF were used for RNA-seq and ITRAQ analysis, and these birds were kept under the same environmental conditions and had free access to feed and water. Abdominal fat tissues were collected right after these birds were euthanized by intramuscular injection of pentobarbital (Sigma, St. Louis, MO, USA) $(40 \mathrm{mg} / \mathrm{kg})$ under deep anesthesia, and then immediately frozen in liquid nitrogen and stored at $-80^{\circ} \mathrm{C}$. The detailed information of selected chickens' abdominal fat weights and abdominal fat percentages were shown in Figure S1a.

\section{Transcriptomic data collection and analysis}

Total RNA from abdominal fat tissues was extracted using the TRIzol reagent (Invitrogen, New Jersey, NJ, USA), and genomic DNA was removed by Dnasel treatment. RNA purity, concentration and integrity were checked by NanoPhotometer ${ }^{\circledR}$ spectrophotometer (IMPLEN, CA, USA), Qubit ${ }^{\circledR}$ RNA Assay Kit in Qubit ${ }^{\circledR}$ 2.0 Flurometer (Life Technologies, CA, USA), and RNA Nano 6000 Assay Kit of the Bioanalyzer 2100 system (Agilent Technologies, CA, USA), respectively. After removal of ribosomal RNA and cleaning-up of rRNA free residue by a Ribo-Zero ${ }^{\mathrm{TM}}$ rRNA Removal Kit (Epicentre, USA), the sequencing libraries were generated using the NEBNext ${ }^{\circledR}$ Ultra ${ }^{\text {TM }}$ Directional RNA Library Prep Kit for Illumina ${ }^{\circledR}$ (NEB, USA) following the manufacturer's recommendations. cDNA fragments of 150-200 bp in length were selected and purified with the AMPure XP system (Beckman Coulter, Beverly, USA). Then, library quality was assessed 
by the Agilent Bioanalyzer 2100 system. Finally, after cluster generation (cBot Cluster Generation System using TruSeq PE Cluster Kit v3-cBot-HS, Illumina), the libraries were sequenced on an Illumina Hiseq 4000 platform, and $150 \mathrm{bp}$ paired-end reads were produced.

After demultiplex and quality filtering of raw data, clean reads were obtained and aligned to the $G$. gallus 6.0 reference genome assembly using HISAT2 (v.2.0.4) [11]. The mapped reads of each sample were assembled and quantified by StringTie (v1.3.1) [12] in a reference-based approach. And differentially expressed genes were identified by DESeq2 [13]. Genes with a corrected p-value $<0.01$ and fold changes $>1.5$ or $<0.67$ were assigned as significantly differentially expressed.

\section{Proteomics}

Protein was extracted according to Damerval et al [14], checked by SDS-PAGE (Figure.S2a) and concentration was determined by the Bradford method [15]. Following reduction, cysteine alkylation, and trypsin digestion, total proteins were treated to obtain peptides, and labeled with iTRAQ 8-plex or iTRAQ 4plex reagents (AB SCIEX, USA), as 113 (LL1), 114 (LL2), 115 (LL3), 116 (LL4), 117 (LL5), 118 (FL1), 119 (FL2), and as 117 (FL3), 118 (FL4), 119 (FL5), respectively. We pooled all samples and labeled as 121 in 8-plex and 4-plex iTRAQ, to calibrate the two iTRAQ experimental data sets. Then, the iTRAQ-labeled peptide mixture was reconstituted and loaded on SCX (strong cation exchange) column, which were subjected to nanoelectrospray ionization, followed by tandem mass spectrometry (MS/MS) in a TripleTOF 5600 system (AB SCIEX, USA).

The MS/MS data were processed with ProteinPilot Software v. 5.0 (AB SCIEX, USA) against Gallus gallus database using the Paragon algorithm [16]. The experimental data from tandem mass spectrometry (MS) were utilized to match the theoretical data to identify proteins, which was performed by the search option (with an emphasis on biological modifications). An automatic decoy database search strategy was used to estimate the false discovery rate (FDR) calculated as the false positive matches divided by total matches, using the PSPEP (Proteomics System Performance Evaluation Pipeline Software, integrated into the ProteinPilot Software). In order to correct the batch effect, the ComBat algorithm of 'sva' $\mathrm{R}$ package was used [17] (Figure S2b). The significantly differentially expressed proteins were identified using the following criteria: 1) peptide groups considered for quantification required at least 2 peptides, and a global FDR less than $1 \%$ was used; and 2) a fold change $>1.5$ or $<0.67$ and with corrected $p$-value $<0.05$.

\section{RT-qPCR analysis}

To validate RNA-Seq results, 20 DEGs with higher expression levels and larger fold changes were validated by RT-qPCR. Ten male birds ( $n=5$ for each line) from the $19^{\text {th }}$ generation of NEAUHLF were used. Total RNA from abdominal fat tissue was reversely transcribed into cDNA using a PrimeScript ${ }^{\mathrm{TM}} \mathrm{RT}$ Reagent Kit (Takara, Dalian, China). FastStart Universal SYBR Green Master kit (Roche) and the ABI 7900 PCR detection system were used to perform RT-qPCR. The program began at $95^{\circ} \mathrm{C}$ for $30 \mathrm{~s}$ for activation, followed by 40 cycles of amplification at $95{ }^{\circ} \mathrm{C}$ for $5 \mathrm{~s}$ and $58{ }^{\circ} \mathrm{C}$ for $30 \mathrm{~s}$. An additional $15 \mathrm{~s}$ at $95{ }^{\circ} \mathrm{C}, 1$ 
min at $60{ }^{\circ} \mathrm{C}$, and $15 \mathrm{~s}$ at $95{ }^{\circ} \mathrm{C}$ were performed for the melt curve stage. The housekeeping gene TATABox binding protein (TBP) was used as the control. RT-qPCR primer pairs were designed by Primer Premier 6.0 and the detailed information were listed in Table S1. The comparative $2^{-\Delta \Delta \mathrm{Ct}}$ method was used to determine the statistical significance.

\section{PRM-MS analysis}

To verify the protein expression level obtained by iTRAQ analysis, 10 DEPs with higher expression levels and larger fold changes were selected for validation. Signature peptides for the target proteins were defined according to the ITRAQ data, and only were unique peptide sequences selected for the PRM-MS analysis (Figure S2c). We randomly selected 6 male birds from the $19^{\text {th }}$ generation ( $n=3$ for each line) of NEAUHLF, and extracted the proteins from abdominal fat tissues, which were prepared following the iTRAQ protocol. Tryptic peptides were loaded on C18 stage tips for desalting prior to reversed-phase chromatography on an Easy nLC-1200 system (Thermo Scientific).

One-hour liquid chromatography gradients with acetonitrile ranging from 5 to $35 \%$ were used, and PRM was performed on a Q-Exactive Plus mass spectrometer (Thermo Scientific). Methods were optimized for collision energy, charge state, and retention times for the most significantly regulated peptides experimentally, using unique peptides of high intensity and confidence for each target protein. The mass spectrometer was operated in positive ion mode and with the following parameters: the full MS1 scan was acquired with the resolution of 70000 (at $200 \mathrm{~m} / \mathrm{z}$ ), automatic gain control (AGC) target values $3.0 \times 10^{6}$, and a $250 \mathrm{~ms}$ maximum ion injection times. Full MS scans were followed by 20 PRM scans at 35000 resolution (at $\mathrm{m} / \mathrm{z} 200$ ) with AGC $3.0 \times 10^{6}$ and maximum injection time $200 \mathrm{~ms}$. The targeted peptides were isolated with a 2.0 Th window and fragmented at a normalized collision energy of 27 in a higher energy dissociation (HCD) collision cell. The raw data were analyzed using Skyline (MacCoss Lab, University of Washington) [18] to get the signal intensities of individual peptide sequences.

For PRM MS data, each sample's average base peak intensity was extracted from the full scan acquisition using RawMeat (version 2.1, VAST Scientific). The normalization factor for sample $\mathrm{N}$ was calculated as $\mathrm{f}_{\mathrm{N}}=$ the average base peak intensity of sample $\mathrm{N}$ divided by the median of average base peak intensities of all samples. The area under curve (AUC) of each transition from sample $\mathrm{N}$ was multiplied by this factor. After normalization, the AUC of each transition was summed to obtain AUCs at the peptide level. Relative protein abundance was defined as the intensity of a certain peptide.

\section{Gene enrichment analysis}

DEGs and DEPs were submitted for the gene ontology (GO) analysis by the clusterProfiler package [19], and the Kyoto Encyclopedia of Genes and Genomes (KEGG) pathway analysis (http://kobas.cbi.pku.edu.cn/kobas3). The thresholds for significant enrichment was set at corrected pvalue $<0.05$

\section{Statistical analysis}


The p-value of DEGs, DEPs, GO term and KEGG pathway enrichment were adjusted by the BenjaminiHochberg $(\mathrm{BH})$ method. Chicken body measurement data were shown as mean $\pm \mathrm{SD}$. Two-tailed student's t-test was used to compare the differences between two groups, and the threshold of significance was set at $p<0.05$.

\section{Results}

\section{Transcriptome profiling}

RNA-Seq generated $77,841,982$ to $95,203,262$ raw reads for each library (Figure S1b). After filtering the low-quality reads, the average number of clean reads was $89,456,223$ and $85,002,558$ for the lean line $(\mathrm{LL})$ and fat line (FL), respectively (Figure S1b). The correlation analysis of the gene expression level between 10 samples was also performed (Figure S1c). Finally, 2167 differentially expressed genes (DEGs) were found, of which 1058 were up-regulated and 1109 down-regulated in LL compared to FL (Fig. 1a, Fig. 1b and Table S2). To verify the accuracy of RNA-Seq data, 20 DEGs were chosen and their expression levels were assayed by RT-qPCR. Except for MAPK6, other genes showed consistent results for both RNA-Seq and RT-qPCR (Fig.1C). Then, the down- and up-regulated DEGs were enriched by GO and KEGG pathway analyses, respectively. GO analysis showed down-regulated DEGs significantly enriched in GO terms such as "oxidation-reduction", "anchored component of membrane", "respiratory chain complex" and "oxidoreductase activity" (Fig. 1d); up-regulated DEGs significantly enriched in GO terms such as "defense response", "response to external biotic stimulus" and "molecular function regulator"(Fig. 1e). The KEGG pathway analysis also revealed that down-regulated DEGs significantly enriched in 8 pathways, including "fatty acid metabolism", "PPAR signaling pathway", "steroid biosynthesis", "metabolic pathways", "wnt signaling pathway", "adherens junction" 『"fatty acid biosynthesis" and "ABC transporters"; up-regulated DEGs significantly enriched in pathways such as "lysosome", "metabolic pathways" and "biosynthesis of amino acid" (Fig.3a). Thus, transcriptome sequencing found that pathways related to fatty acid metabolism could be important in fat deposition differences in our divergently selected chicken lines.

\section{iTRAQ-based Proteomics}

To better understand the potential mechanisms underlying differential abdominal fat deposition between fat and lean broilers, iTRAQ-based proteomics was also performed. Eight-plex iTRAQ generated 61,498 spectra and 18,672 unique peptides (matching to 2,424 proteins); four-plex iTRAQ generated 45,203 spectra and 14,300 unique peptides (matching to 2,185 proteins). In addition, after stringent selection of unique peptides (95\% confidence limit and global FDR $<1 \%$ ), we identified 2,137 and 1,727 proteins in the two iTRAQ experiments, respectively. Finally, 199 differentially expressed proteins (DEPs) were identified between the two chicken lines, of which 109 were up-regulated and 90 down-regulated in LL compare to FL (Fig.2a). The heat map of hierarchical clustering of DEPs was shown in Fig.2b, and detailed information about every DEP was listed in Table S3. To validate the iTRAQ data, we selected 10 DEPs for 
the PRM analysis, and 9 of 10 proteins were successfully quantified. The PRM results of these nine proteins were consistent with our iTRAQ data (Fig.2c).

Next, GO enrichment and KEGG pathway analysis were performed to determine the function of the downand up-regulated DEPs. For the biological process (BP) category, "fatty acid biosynthetic process", "monocarboxylic acid biosynthetic process" and "fatty acid metabolic process" were significantly enriched by down-regulated DEPs (Fig. 2d). In addition, "endoplasmic reticulum lumen" and "calcium ion binding" were the most representative GO terms enriched by up-regulated DEPs for the cellular component (CC) and the molecular function (MF), respectively (Fig.2e). KEGG pathway analysis showed that the down-regulated DEPs were mainly enriched in "metabolic pathways", and lipid metabolismassociated pathways, such as "PPAR signaling pathway", "Insulin signaling pathway", "fatty acid biosynthesis", "biosynthesis of unsaturated fatty acids" and "fatty acid metabolism"; and up-regulated DEPs were significantly enriched in pathways such "metabolic pathways" and "lysosome" (Fig.3a). In support of our transcriptome analysis, proteome analysis further discovered that pathways related to fatty acid metabolism are likely important in fat deposition differences between our fat and lean chicken lines.

\section{Integrated transcriptome and proteome analysis}

In order to further distinguish the critical DEGs and DEPs that may affect chicken abdominal fat deposition, integrated transcriptome and proteome analysis was conducted by combined analysis on our RNA-Seq and iTRAQ data. First, we compared the DEGs and DEPs and found 32 genes were overlapped. It was worth noting that except for MAP4, other genes show the same expression tendency (Fig.3c and Table 1), suggesting these genes could be the key genes involved in the regulation of abdominal fat deposition.

Second, by comparing the pathways obtained after DEGs and DEPs enrichment analysis, except for the "metabolic pathways", we found that there were four overlapped pathways, three of which enriched by down-regulated DEGs and DEPs were related to lipid metabolism, such as "fatty acid metabolism", "PPAR signaling pathway", and "fatty acid biosynthesis", the only one enriched by both up-regulated DEGs and DEPs was "lysosome" (Fig.3a and 3b), including 37 genes that may important for fat deposition. Together, 63 key DEGs/DEPs [32 significantly differentially expressed at both mRNA and protein levels (Fig. $3 \mathrm{C}$ and Table 1), and 37 genes in overlapped pathways with acetyl-CoA carboxylase alpha (ACACA), stearoyl-CoA desaturase (SCD), fatty acid synthase (FASN), lipoprotein lipase (LPL), acyl-CoA synthetase long-chain family member 1 (ACSL1), and cathepsin S (CTSS) appear twice] that may affect chicken abdominal fat deposition were discovered through our integrated transcriptome and proteome analysis (Table 1).

\section{Discussion}

Adipose tissue is no longer viewed as a passive repository for triacylglycerol storage and a source of free fatty acids but as an active endocrine and paracrine organ secreting an ever increasing number of 
cytokines that participate in diverse metabolic processes including food intake, regulation of energy balance, insulin action, glucose and lipid metabolism, angiogenesis and vascular remodeling, regulation of blood pressure, and coagulation [20-21]. Excess adipose tissue leads to obesity and metabolic syndrome, such as insulin resistance, type 2 diabetes, heart disease, atherosclerosis and hypertension [22]. Exploring the molecular mechanism of adipose development and fat deposition is helpful for the therapy of obesity and related metabolic diseases. Our fat and lean broilers have similar body weight but acquire a divergent abdominal fat content. So, it is the ideal animal model to study the molecular basis of fat deposition. In the current study, we combined RNA-Seq and iTRAQ techniques on abdominal adipose tissues from 7-week-old FL and LL broilers, and identified a number of key DEGs and DEPs that may affect fat deposition (Table 1). These genes are mainly involved in lipid metabolism associated processes, such as long-chain fatty acids uptake, in situ lipogenesis (fatty acid and cholesterol synthesis), and lipid droplets accumulation.

\section{Long-chain fatty acid uptake}

In poultry, fatty acids are taken up by the adipose tissue, which mainly come from triglycerides in plasma lipoproteins (such as VLDL) synthesized and packaged by the liver, and also from triglycerides in portomicrons (PM) assembled by long-chain fatty acids in dietary fat [23]. The triglycerides contained in VLDL and PM are hydrolyzed by lipoprotein lipase (LPL) located in adipose tissue-lined endothelial cells to produce free fatty acids, which can be taken up by adipocytes and then re-esterified and stored in lipid droplet as triglycerides [24]. Previous studies suggested that increased uptake of fatty acids in abdominal adipose tissue is a major cause of obesity in chickens [25]. In general, most cells show less ability in longchain fatty acid uptake, whereas adipocytes and cardiomyocytes can efficiently and specifically absorb long-chain fatty acids [26]. In the present study, DEG [caveolin 1 (CAV1), ACSL 1, and solute carrier family 27 member 6 (SLC27A6)] and DEPs [LPL, CAV1, and ACSL1] were implicated in long-chain fatty acid uptake. So, we speculate that long-chain fatty acid uptake may play an important role in chicken adiposity.

LPL is considered to be a rate-limiting enzyme in fat accretion in chicken adipose tissue [27], responsible for decomposing triglycerides in VLDL or PM to release free fatty acids. CAV1 was identified as the main plasma membrane fatty acid binding protein in adipocytes that can bind long-chain fatty acids with high affinity [28]. Lack of CAV1 results in the loss of caveolae and defects in long-chain fatty acid uptake in adipocytes [29]. In addition, CAV1 can bind to the long chain fatty acids on the inner leaflet of the lipid bilayer, and transport fatty acids to the subcellular membrane compartment through vesicle-mediated transport [30]. ACSL1 is an acyl-CoA synthetase, and functions as long-chain fatty acid transport protein in adipocyte [31]. The first step in using long-chain fatty acids in cells is their esterification reaction with $\mathrm{CoA}$, and this reaction is catalyzed by acyl-CoA synthetase. In humans, there are two related long-chain fatty acid activation-related protein families: fatty acid transporters (FATP) and long-chain acyl-CoA synthetase (ACSLs). ACSL1 was found to co-localize with FATP1 in a small number of 3T3-L1 cells [32]. Furthermore, ACSL1 can promote fatty acid uptake into cells depending on their expression levels [3334]. SLC27A6, also named FATP6, is a kind of FATP that can enhance the uptake of long-chain and very- 
long-chain fatty acids into cells [35]. In the present study, the expression levels of LPL, ACSL1, CAV1 and SLC27A6 were significantly higher in the FL adipose tissue, indicating the adipose tissues of the fat broilers have stronger long-chain fatty acid uptake ability to synthesize more triglycerides.

\section{Fatty acids synthesis}

The liver is widely considered to be the main site of de novo lipid synthesis in avian species, with more than $70 \%$ of de novo fatty acid synthesis occurring in liver tissue [36], contradictory to the findings in the present study that a large number of lipogenic genes expressed in chicken abdominal fat tissue. Recent studies have also shown that the lipid synthesis ability of avian adipose tissue may be underestimated. Resnyk et al. [37] performed microarray analysis on 9-week-old chicken abdominal fat tissue and found many genes associated with lipogenesis were highly expressed in fat chicken. Similarly, one RNA-Seq analysis on 7-week-old broilers showed a large number of lipogenic genes were also upregulated in abdominal adipose tissues from fat chicken [38]. Another RNA sequencing analysis showed that the 7-week-old fast growth chickens (fatter than slow growth chickens) over-express numerous lipogenic genes in adipose tissue, which should enhance in situ lipogenesis and ultimately adiposity [39]. Intriguingly, in the present study, we also found several key genes associated with fatty acids synthesis, including DEGs [ACACA, fatty acid desaturase 2 (FADS2), SCD, 3-hydroxyacyl-CoA dehydratase 1 (HACD1), HACD2, FASN, ACSL 1, acyl-CoA synthetase bubblegum family member 1 (ACSBG1), and 3-oxoacyl-ACP

synthase, mitochondrial (OXSM)] and DEPs [ACACA, FASN, SCD, ACSL1, acyl-CoA oxidase 1 (ACOX1), and hydroxysteroid 17-beta dehydrogenase 4 (HSD17B4)]. KEGG analysis showed that ACACA, OXSM, FASN, ACSBG1 and ACSL1 were enriched in fatty acid biosynthesis pathway, and FADS2, SCD, HACD1, HACD2, HSD17B4 and ACOX1 were enriched in the biosynthesis of unsaturated fatty acids pathway (Fig.3b and Table 1). It is worth noting that two proteins (ACACA and SCD) can work as critical enzymes to synthesize fatty acids. ACACA is the rate-limiting enzyme in fatty acid biosynthesis, which can catalyze the synthesis of malonyl-CoA from two molecules of acetyl-CoA, and produce fatty acids under the action of fatty acid synthase [40]. SCD is a rate-limiting enzyme that catalyzes the formation of monounsaturated fatty acids from saturated fatty acids [38].

Thus, we found that the expression levels of genes related to fatty acid synthesis were significantly higher in the fat line, suggesting the adipose tissues in fat birds have stronger ability of triglycerides synthesis in adipocytes.

\section{Cholesterol synthesis}

At the cellular level, the deposition of adipose tissue is the result of the increase of the number of adipocytes (adipogenesis) and the size of single fat cells (triglyceride and cholesterol accumulation in lipid droplets) [42-43].

Adipose tissue is the major site for the storage of cholesterol, containing both free and esterified forms of cholesterol [44]. In the current study, some critical DEGs [epoxide hydrolase 2, cytoplasmic (EPHX2), cytochrome p450 oxidoreductase (POR), and hydroxysteroid 17-beta dehydrogenase 7 
(HSD17B7)] and DEPs [acetyl-CoA acetyltransferase 1 (ACAT1), EPHX2, POR, and HSD17B7] were related to cholesterol synthesis. ACAT1 is an acetyl-coenzyme A acetyltransferase, which can catalyze the formation of cholesteryl esters from cholesterol and long-chain fatty acyl-CoAs [45]. EPHX2 is a member of the epoxide hydrolase family, and the N-terminal activity of EPHX2 can increase the cell's cholesterol level [46-47]. POR is a microsomal membrane-associated protein of two types: type I and type II, of which type II is responsible for cholesterol synthesis [48]. Lanosterol-14a-demethylase and squalene monooxygenase can participate in cholesterol biosynthesis and require POR as the electron donor [4950]. HSD17B7 belongs to the 17 $\beta$-hydroxysteroid dehydrogenase (17 $\beta-H S D)$ family that catalyze the conversion of the keto group on the 17th carbon in steroids to their $17 \beta$-hydroxy forms, and function as the 3-ketosteroid reductase of cholesterol biosynthesis [51]. In present study, ACAT1, EPHX2, POR and HSD17B7 were all up-regulated in abdominal adipose tissue of fat line in the current study, suggesting the fat broilers could accumulate more cholesterol to expand the size of adipocytes.

\section{Lipid droplet accumulation}

Lipid droplets are dynamic organelles involved in intracellular lipid metabolism in almost all eukaryotic cells, and in white adipocytes, the large unique lipid droplet occupies most of the cell space and volume [52].

In the present study, perilipin1 (PLIN1), PLIN4 and CAV1 associated with lipid droplet accumulation were up-regulated in FL compared with LL. PLINs are proteins that coat lipid droplets in adipocytes, which control the lipolysis of stored neutral lipids by cytosolic lipases. PLIN1 is the most abundant lipid droplet coat protein, and plays a crucial role in restricting adipose lipolysis under basal or fed conditions [53]. PLIN4 mainly exists in white adipose tissue and is associated with tiny nascent lipid droplets. As a lipid droplet coat protein, PLIN4 can quickly package newly synthesized triacylglycerol, and store energy to the greatest extent during excessive nutrition [54]. Another lipid droplet coat protein is CAV1, which is an essential component for the assembly of caveola organelles in highly differentiated cells, such as adipocytes. CAV1 usually plays a key structural role in the accumulation of lipid droplets in adipocytes, since the deletion of CAV1 can reduce lipid accumulation, which leads to progressive atrophy of white adipose tissue [55]. PLIN1, PLIN4 and CAV1 were up-regulated in the adipose tissue of fat line, indicating that fat birds may accumulate more lipid droplets in adipocytes than the lean birds.

For LL chickens, there are numerous down-regulated DEGs [solute carrier family 11 member 1 (SLC11A1), lipopolysaccharide induced TNF factor (LITAF), lysosomal protein transmembrane 5 (LAPTM5), hexosaminidase subunit beta $(H E X B), G M 2$ ganglioside activator $(G M 2 A)$, deoxyribonuclease 2 beta (DNASE2B), cathepsin V (CTSV), cathepsin S (CTSS), cathepsin H (CTSH), cathepsin C (CTSC), clathrin light chain $\mathrm{A}(C L T A)$, ATPase $\mathrm{H}^{+}$transporting V0 subunit $\mathrm{d} 2$ (ATP6VOD2), arylsulfatase $\mathrm{B}(A R S B)$, and acid phosphatase 5, tartrate resistant (ACP5)] and DEPs [palmitoyl-protein thioesterase 1 (PPT1), alpha-Nacetylgalactosaminidase (NAGA), glucosamine (N-acetyl)-6-sulfatase (GNS), cathepsin D (CTSD), cathepsin S (CTSS), and galactosidase alpha (GLA)] significantly enriched in "lysosome" by KEGG analysis. Lysosomes are small organelles (100-500 nm diameter) that contained proteasomes, lipases 
and nucleases [56]. Autophagy is closely related to lysosomes because it targets defective organelles to lysosomes for degradation [57]. Researchers reported that autophagy plays a complex role in adipose deposition. Zhao et al. [58] revealed that the activation of autophagy can suppress the adipogenesis of human adipose derived stem cells. Singh et al. [59] first reported the similarities in regulation and function between lipolysis and autophagy in hepatocytes such as autophagy is required for lipid droplet breakdown, and inhibition of autophagy will increase lipid storage. Another study shown inhibition of autophagy by Bisphenol A exposure will result in decreased lipid droplet degradation and increased ROS levels [60]. Other studies also shown that autophagy plays essential roles in lipolysis, which could eliminate fat [61-62], although many researches have shown that autophagy plays a positive role in adipocyte differentiation [63-64].

In the present study, numerous key DEGs and DEPs related to lysosome pathway were up-regulated in lean line, speculating that the autophagy-lysosome pathway was activated in the abdominal adipose tissue of lean birds, which promote lipolysis in adipocytes and reduce lipid droplets accumulation. Herein, through the joint analysis of transcriptome and proteome, we found many key genes that may affect chicken fat deposition (Table 1). The differential expression and molecular function of these genes likely lead to the differential accumulation of abdominal fat content, although some of them have not been reported to be directly related to adiposity, such as amino acid metabolism-related genes (ADP ribosylation factor like GTPase 6 interacting protein 5 and glutathione S-transferase theta 1-like 1) and oxidation-reduction-related genes (steroid 5 alpha-reductase 3, glycerol-3-phosphate dehydrogenase 2 , mitochondrial, retinol saturase and vesicle amine transport 1). Functions of these genes in adipose tissue development and fat deposition awaits further investigation.

\section{Conclusion}

In summary, molecular differences related to long-chain fatty acid uptake, in situ lipogenesis (fatty acid and cholesterol synthesis), and lipid droplets accumulation were discovered to exist between the fat and lean chicken lines, which may contribute to the striking differences of abdominal fat deposition.

\section{Abbreviations}

AGC: Automatic gain control; AUC: Area under curve; BP: Biological process; CC: Cellular component; DEGs: Differentially expressed genes; DEPs: Differentially expressed proteins; FDR: False discovery rate; FL: Fat line; GO: Gene ontology; HCD: higher energy dissociation; iTRAQ: isobaric tags for relative and absolute quantitation; KEGG: Kyoto encyclopedia of genes and genomes; LL: Lean line; MF: Molecular function; MS: Mass spectrometry; NEAUHLF: Northeast Agricultural University broiler lines divergently selected for abdominal fat content; PM: Portomicrons; PRM: Parallel Reaction Monitoring; RT-qPCR: Realtime quantitative PCR; SDS-PAGE: Sodium dodecyl sulfate-polyacrylamide gel electrophoresis; VLDL: Very low-density lipoprotein.

\section{Declarations}


Acknowledgments

The authors thank the members of Poultry Research Group in College of Animal Science and Technology at Northeast Agricultural University for hatching eggs and laboratory technical analyses.

\section{Funding}

This study was supported by China Agriculture Research System (No. CARS-41) and the National 863 project of China (No. 2013AA102501). The funders had no role in study design, data collection and analysis, decision to publish, or preparation of the manuscript.

\section{Availability of data and materials}

The transcriptomics datasets generated during the current study are available in NCBI SRA [PRJNA354990 (SRR5055412 to SRR5055416 for FL and SRR5055375 to SRR5055379 for LL)], and other data generated or analyzed during this study are included in this published article and its supplementary information files.

\section{Authors' contributions}

LJW performed the experiments, analyzed data, drafted and wrote the manuscript. LL, RD and CL participated to the sample collection, and helped perform the experiments. PFG participated in the analysis of data. NW helped design the study. HL, ZQD and BHC contributed to the experimental design and manuscript revision. All authors read and approved the final manuscript.

\section{Ethics approval and consent to participate}

All animal work was conducted following the guidelines for the care and use of experimental animals, established by the Ministry of Science and Technology of the People's Republic of China (Approval number: 2006-398), and also approved by the Laboratory Animal Management Committee of Northeast Agricultural University.

\section{Consent for publication}

Not applicable.

\section{Competing interests}

The authors declare that they have no competing interests.

\section{References}

1. Wu GQ, Deng XM, Li JY, Li N, Yang N. A potential molecular marker for selection against abdominal fatness in chickens. Poult Sci. 2006; 85:1896-9. 
2. Chen J, Ren X, Li L, Lu S, Chen T, Tan L, et al. Integrative analyses of mRNA expression Profile Reveal the Involvement of IGF2BP1 in Chicken Adipogenesis. Int J Mol Sci. 2019; 20:2923.

3. Guo L, Sun B, Shang Z, Leng L, Wang Y, Wang N, et al. Comparison of adipose tissue cellularity in chicken lines divergently selected for fatness. Poult Sci. 2011; 90:2024-34.

4. Wang $\mathrm{H}$, Li H, Wang $\mathrm{Q}$, Wang $\mathrm{Y}$, Han $\mathrm{H}$, Shi $\mathrm{H}$. Microarray analysis of adipose tissue gene expression profiles between two chicken breeds. J Biosci .2006; 31:565-73.

5. Wang HB, Hui L, Wang QG, Zhang XY, Wang SZ, Wang YX, Wang XP. Profiling of chicken adipose tissue gene expression by genome array. BMC Genomics. 2007; 8:193.

6. Wang D, Wang N, Li N, Li H. Identification of differentially expressed proteins in adipose tissue of divergently selected broilers. Poult Sci. 2009; 88:2285-92.

7. Wu CY, Wu YY, Liu CD, Wang YX, Na W, Wang N, et al. Comparative proteome analysis of abdominal adipose tissues between fat and lean broilers. Proteome Sci. 2016; 14:9.

8. Zhang H, Jiang H, Fan Y, Chen Z, Li M, Mao Y, et al. Transcriptomics and iTRAQ-proteomics analyses of bovine mammary tissue with streptococcus agalactiae-induced mastitis. J Agric Food Chem. 2018; 66:11188-96.

9. Na W, Wu YY, Gong PF, Wu CY, Cheng BH, Wang YX, et al. Embryonic transcriptome and proteome analyses on hepatic lipid metabolism in chickens divergently selected for abdominal fat content. BMC Genomics. 2018; 19:384.

10. Xu Y, Qian H, Feng X, Xiong Y, Lei M, Ren Z, et al. Differential proteome and transcriptome analysis of porcine skeletal muscle during development. J Proteomics .2012; 75:2093-108.

11. Kim D, Langmead B, Salzberg SL. HISAT: a fast spliced aligner with low memory requirements. Nat Methods. 2015; 12:357-60.

12. Pertea M, Pertea GM, Antonescu CM, Chang TC, Mendell JT, Salzberg SL.StringTie enables improved reconstruction of a transcriptome from RNA-seq reads. Nat Biotechnol. 2015; 33:290-5.

13. Love MI, Huber W, Anders S. Moderated estimation of fold change and dispersion for RNA-seq data with DESeq2. Genome Biol. 2014; 15:550.

14. Damerval C, De Vienne D, Zivy M, Thiellement $H$, Eacute. Technical improvements in two-dimensional electrophoresis increase the level of genetic variation detected in wheat-seedling proteins. Electrophoresis. 2010; 7:52-4.

15. Bradford MM. A rapid and sensitive method for the quantitation of microgram quantities of protein utilizing the principle of protein-dye binding. Anal Biochem. 1976; 72:248-54.

16. Shilov IV, Seymour SL, Patel AA, Loboda A, Tang WH, Keating SP, et al. The Paragon Algorithm, a next generation search engine that uses sequence temperature values and feature probabilities to identify peptides from tandem mass spectra. Mol Cell. Proteomics 2007; 6:1638-55.

17. Varma S. Blind estimation and correction of microarray batch effect. PLoS One. 2020; 9;15:e0231446. 
18. MacLean B, Tomazela DM, Shulman N, Chambers M, Finney GL, Frewen B, et al. Skyline: an open source document editor for creating and analyzing targeted proteomics experiments. Bioinformatics. 2010; 26:966-8.

19. Yu G, Wang LG, Han Y, He QY. clusterProfiler: an R package for comparing biological themes among gene clusters. OMICS. 2012; 16:284-7.

20. Ferroni P, Basili S, Falco A, Davì G. Inflammation, insulin resistance, and obesity. CurrAtheroscler Rep. 2004; 6:424-31.

21. Lau DC. Adipose tissue growth and differentiation: view from the chair. Int J ObesRelatMetabDisord. 2000;24 Suppl 4:S20-2.

22. Grundy SM, Brewer HB Jr, Cleeman JI, Smith SC Jr, Lenfant C; Definition of metabolic syndrome: Report of the National Heart, Lung, and Blood Institute/American Heart Association conference on scientific issues related to definition. Circulation. 2004; 109:433-8.

23. Griffin H, Hermier D.Leanness in domestic birds: Plasma lipoprotein metabolism and fattening in poultry. In: Leclercq B, Whitehead CC,editors.Butterworth. London: Academic;1988. p 175-201.

24. Ramenofsky M, Bird migration:Fat storage and fat metabolism in relation to migration. In: Gwinner $E$, editors. Springer. Berlin/Heidelberg: Academic;1990. p 214-231.

25. Leclercq B, Hermier D, Guy G, Salichon MR, Quignard-Boulangé A, Ardouin B, et al. Evidence of enhanced storage capacity in adipose tissue of genetically fat chickens. J Nutr. 1989; 119:1369-75.

26. Schaffer JE, Lodish HF, Molecular mechanism of long-chain fatty acid uptake. Trends Cardiovasc Med. 1995; 5:218-24.

27. Sato K, Akiba Y, Chida Y, Takahashi K, Lipoprotein hydrolysis and fat accumulation in chicken adipose tissues are reduced by chronic administration of lipoprotein lipase monoclonal antibodies. Poult Sci. 1999; 78:1286-91.

28. Trigatti BL, Anderson RG, Gerber GE. Identification of caveolin-1 as a fatty acid binding protein. Biochem Biophys Res Commun. 1999; 255:34-9.

29. Pohl J, Ring A, Ehehalt R, Schulze-Bergkamen H, Schad A, Verkade P, et al. Long-chain fatty acid uptake into adipocytes depends on lipid raft function. Biochemistry .2004; 43:4179-87.

30. Meshulam T, Simard JR, Wharton J, Hamilton JA, Pilch PF. Role of caveolin-1 and cholesterol in transmembrane fatty acid movement. Biochemistry. 2006; 45:2882- 93.

31. Schaffer JE, Lodish HF. Expression cloning and characterization of a novel adipocyte long chain fatty acid transport protein. Cell. 1994; 79:427-36.

32. Gargiulo CE, Stuhlsatz-Krouper SM, Schaffer JE. Localization of adipocyte long-chain fatty acyl-CoA synthetase at the plasma membrane. J Lipid Res. 1999; 40:881-92.

33. Krammer J, Digel M, Ehehalt F, Stremmel W, Füllekrug J, Ehehalt R. Overexpression of CD36 and acylCoA synthetases FATP2, FATP4 and ACSL1 increases fatty acid uptake in human hepatoma cells. Int J Med Sci. 2011; 8:599-614. 
34. Tong F, Black PN, Coleman RA, DiRusso CC. Fatty acid transport by vectorial acylation in mammals: roles played by different isoforms of rat long-chain acyl-CoA synthetases. Arch Biochem Biophys. 2006; 447:46-52.

35. Stahl A. A current review of fatty acid transport proteins (SLC27). Pflugers Arch. 2004; 447:722-7.

36. Leveille GA. In vitro hepatic lipogenesis in the hen and chick. Comp Biochem Physiol. 1969; 28:431-5.

37. Resnyk CW, Carré W, Wang X, Porter TE, Simon J, Le Bihan-Duval Eet al. Transcriptional analysis of abdominal fat in genetically fat and lean chickens reveals adipokines, lipogenic genes and a link between hemostasis and leanness. BMC Genomics. 2013; 14:557.

38. Resnyk CW, Chen C, Huang H, Wu CH, Simon J, Le Bihan-Duval E, et al. RNA-Seq analysis of abdominal fat in genetically fat and lean chickens highlights a divergence in expression of genes controlling adiposity, hemostasis, and lipid metabolism. PLoS One. 2015; 10:e0139549.

39. Resnyk CW, Carré W, Wang X, Porter TE, Simon J, Le Bihan-Duval E, et al. Transcriptional analysis of abdominal fat in chickens divergently selected on bodyweight at two ages reveals novel mechanisms controlling adiposity: validating visceral adipose tissue as a dynamic endocrine and metabolic organ. BMC genomics. 2017; 18:626.

40. Collins JM, Neville MJ, Pinnick KE, Hodson L, Ruyter B, van Dijk TH, et al. De novo lipogenesis in the differentiating human adipocyte can provide all fatty acids necessary for maturation. J Lipid Res. 2011; 52:1683-92.

41. Ntambi JM. Regulation of stearoyl-CoA desaturase by polyunsaturated fatty acids and cholesterol. $J$ Lipid Res. 1999; 40:1549-58.

42. Kovanen PT, Nikkilä EA, Miettinen TA: Regulation of cholesterol synthesis and storage in fat cells. J Lipid Res. 1975; 16:211-23.

43. Rosen ED, Spiegelman BM. Adipocytes as regulators of energy balance and glucose homeostasis. Nature. 2006; 444 :847-53.

44. Krause BR, Hartman AD. Adipose tissue and cholesterol metabolism. J Lipid Res. 1984; 25:97-110.

45. Antalis CJ, Arnold T, Lee B, Buhman KK, Siddiqui RA. Docosahexaenoic acid is a substrate for ACAT1 and inhibits cholesteryl ester formation from oleic acid in MCF-10A cells. Prostaglandins Leukot Essent Fatty Acids. 2009; 80:165-71.

46. EnayetAllah AE, Luria A, Luo B, Tsai H-J, Sura P, Hammock BDet al. Opposite regulation of cholesterol levels by the phosphatase and hydrolase domains of soluble epoxide hydrolase. TJ Biol. Chem2008; 283:36592-8.

47. Domingues MF, Callai-Silva N, Piovesan AR, Carlini CR. Soluble Epoxide Hydrolase and Brain Cholesterol Metabolism. Front Mol Neurosci. 2020; 12:325.

48. Aguilar A, De Luca F, Wu S. P450 oxidoreductase expressed in rat chondrocytes modulates chondrogenesis via cholesterol- and Indian Hedgehog-dependent mechanisms. Endocrinology. 2009; 150:2732-9. 
49. Ono T, Bloch K. Solubilization and partial characterization of rat liver squalene epoxidase. J Biol Chem. 1975; 250:1571-9.

50. Debeljak N, Fink M, Rozman D. Many facets of mammalian lanosterol 14alpha-demethylase from the evolutionarily conserved cytochrome P450 family CYP51. Arch Biochem Biophys. 2003; 409:159-71.

51. Marijanovic Z, Laubner D, Moller G, Gege C, Husen B, Adamski J, Breitling R. Closing the gap: identification of human 3-ketosteroid reductase, the last unknown enzyme of mammalian cholesterol biosynthesis. Mol Endocrinol. 2003; 17:1715-25.

52. Konige $\mathrm{M}$, Wang $\mathrm{H}$, Sztalryd $\mathrm{C}$. Role of adipose specific lipid droplet proteins in maintaining whole body energy homeostasis. Biochim Biophys Acta. 2014; 1842:393-401.

53. Sztalryd C, Brasaemle DL. The perilipin family of lipid droplet proteins: Gatekeepers of intracellular lipolysis. Biochim Biophys Acta Mol Cell Biol Lipids. 2017; 1862:1221-32.

54. Mardani I, Tomas Dalen K, Drevinge C, Miljanovic A, Ståhlman M, Klevstig M, et al. Plin2-deficiency reduces lipophagy and results in increased lipid accumulation in the heart. Sci Rep. 2019; 9:6909.

55. Wolins NE, Quaynor BK, Skinner JR, Schoenfish MJ, Tzekov A, Bickel PE. S3-12, Adipophilin, and TIP47 package lipid in adipocytes. J Biol Chem.2005; 280:19146-55.

56. Hurley JH, Schulman BA. Atomistic autophagy: the structures of cellular self-digestion. Cell. 2014; 157:300-11.

57. Zhao L, Ha JH, Okla M, Chung S. Activation of autophagy and AMPK by gamma-tocotrienol suppresses the adipogenesis in human adipose derived stem cells. Mol Nutr Food Res. 2014; 58:56979.

58. Mao Y, Yu F, Wang J, et al. Autophagy: a new target for nonalcoholic fatty liver disease therapy[J]. Hepatic medicine: evidence and research, 2016, 8: 27.

59. Singh R, Kaushik S, Wang Y, Xiang Y, Novak I, Komatsu M, Tanaka K, Cuervo AM, Czaja MJ. Autophagy regulates lipid metabolism. Nature. 2009; 30; 458:1131-5.

60. Song D, Chen Y, Wang B, Li D, Xu C, Huang H, Huang S, Liu R. Bisphenol A inhibits autophagosomelysosome fusion and lipid droplet degradation. Ecotoxicol Environ Saf. 2019; 183:109492.

61. Zechner R, Madeo F. Cell biology: Another way to get rid of fat. Nature. 2009; 30; 458:1118-9.

62. Lizaso A, Tan KT, Lee YH. $\beta$-adrenergic receptor-stimulated lipolysis requires the RAB7-mediated autolysosomal lipid degradation. Autophagy. 2013; 9:1228-43.

63. Zhang W, Li P, Wang S, Cheng G, Wang L, Mi X, Su X, Wang Y, Zan L. TP53INP2 promotes bovine adipocytes differentiation through autophagy activation. Animals (Basel). 2019; 9:1060.

64. Guo L, Huang JX, Liu Y, Li X, Zhou SR, Qian SW, Liu Y, Zhu H, Huang HY, Dang YJ, Tang QQ. Transactivation of Atg4b by C/EBP $\beta$ promotes autophagy to facilitate adipogenesis. Mol Cell Biol. 2013; 33:3180-90.

65. Cohen AW, Razani B, Schubert W, Williams TM, Wang XB, et al. Role of caveolin-1 in the modulation of lipolysis and lipid droplet formation. Diabetes.2004; 53:1261-70. 


\section{Tables}

Table 1. Key DEGs and DEPs that may affect chicken abdominal fat deposition 


\begin{tabular}{|c|c|c|c|c|}
\hline Gene name & $\begin{array}{l}\text { Gene } \\
\text { symbol }\end{array}$ & $\begin{array}{l}\text { Gene } \\
\log _{2}(\mathrm{LL} / \mathrm{FL})\end{array}$ & $\begin{array}{l}\text { Protein } \\
\log _{2}(\mathrm{LL} / \mathrm{FL})\end{array}$ & $\begin{array}{l}\text { Functional } \\
\text { annotation }\end{array}$ \\
\hline abhydrolase domain containing 12B & ABHD12B & -1.2892 & -1.2753 & Hydrolase activity \\
\hline acetyl-CoA carboxylase alpha & ACACA & -0.7822 & -0.9434 & $\begin{array}{ll}\text { Fatty } & \text { acid } \\
\text { biosynthesis } & \end{array}$ \\
\hline acyl-CoA dehydrogenase long chain & ACADL & -0.5793 & - & $\begin{array}{l}\text { Fatty } \\
\text { degradation }\end{array}$ \\
\hline acyl-CoA dehydrogenase, short/branched chain & ACADSB & -0.8121 & - & $\begin{array}{l}\text { Fatty } \\
\text { degradation }\end{array}$ \\
\hline acetyl-CoA acetyltransferase 1 & ACAT1 & - & -0.8863 & $\begin{array}{l}\text { Cholesterol } \\
\text { biosynthesis }\end{array}$ \\
\hline acyl-CoA oxidase 1 & ACOX1 & - & -0.5798 & $\begin{array}{l}\text { Biosynthesis } \\
\text { unsaturated } \\
\text { acids }\end{array}$ \\
\hline acid phosphatase 5 , tartrate resistant & ACP5 & 1.3632 & - & Lysosome \\
\hline acyl-CoA synthetase bubblegum family member 1 & ACSBG1 & -1.1784 & - & $\begin{array}{l}\text { Fatty } \\
\text { biosynthese }\end{array}$ \\
\hline acyl-CoA synthetase long-chain family member 1 & ACSL1 & -1.3302 & -2.3485 & $\begin{array}{l}\text { Fatty } \\
\text { biosynthesis } \\
\text { uptake }\end{array}$ \\
\hline annexin A1 & ANXA1 & -1.3816 & -2.0371 & Phagocytosis \\
\hline $\begin{array}{l}\text { ADP ribosylation factor like GTPase } 6 \text { interacting } \\
\text { protein } 5\end{array}$ & ARL6IP5 & -0.7094 & -2.3511 & $\begin{array}{l}\text { L-glutamate } \\
\text { transmembrane } \\
\text { transport }\end{array}$ \\
\hline arylsulfatase B & ARSB & 0.7599 & - & Lysosome \\
\hline ATPase $\mathrm{H}^{+}$transporting V0 subunit $\mathrm{d} 2$ & ATP6V0D2 & 1.6667 & - & Lysosome \\
\hline $\begin{array}{l}\text { ATPase, aminophospholipid transporter (APLT), } \\
\text { class I, type } 8 \mathrm{~A} \text {, member } 1\end{array}$ & ATP8A1 & -1.2460 & -0.8970 & $\begin{array}{l}\text { Phospholipid } \\
\text { translocation }\end{array}$ \\
\hline caveolin 1 & CAV1 & -0.8912 & -1.8720 & $\begin{array}{ll}\text { Fatty acids } & \text { uptake; } \\
\text { Lipid } & \text { droplet } \\
\text { accumulation } & \end{array}$ \\
\hline clathrin light chain A & CLTA & 0.7127 & - & Lysosome \\
\hline cathepsin C & CTSC & 1.1374 & - & Lysosome \\
\hline cathepsin D & CTSD & - & 0.7765 & Lysosome \\
\hline cathepsin $\mathrm{H}$ & $\mathrm{CTSH}$ & 1.2896 & - & Lysosome \\
\hline cathepsin S & CTSS & 1.2638 & 1.2010 & Lysosome \\
\hline cathepsin V & CTSV & 0.6707 & - & Lysosome \\
\hline deoxyribonuclease 2 beta & DNASE2B & 0.9856 & - & Lysosome \\
\hline erythrocyte membrane protein band 4.1 & ЕРB41 & -1.0415 & -1.7676 & Cell junction \\
\hline epoxide hydrolase 2 , cytoplasmic & EPHX2 & -1.0052 & -1.3117 & $\begin{array}{l}\text { Cholesterol } \\
\text { biosynthesis }\end{array}$ \\
\hline fatty acid desaturase 2 & FADS2 & -1.5794 & - & $\begin{array}{l}\text { Biosynthesis } \\
\text { unsaturated } \\
\text { acids }\end{array}$ \\
\hline fatty acid synthase & FASN & -0.8492 & -1.8644 & $\begin{array}{l}\text { Fatty } \\
\text { biosynthesis }\end{array}$ \\
\hline guanylate binding protein & GBP & 1.1099 & 1.3815 & GTP binding \\
\hline galactosidase alpha & GLA & - & 0.6289 & Lysosome \\
\hline GM2 ganglioside activator & GM2A & 1.4721 & - & Lysosome \\
\hline glucosamine (N-acetyl)-6-sulfatase & GNS & - & 0.8658 & Lysosome \\
\hline glypican 4 & GPC4 & -1.2517 & -2.4619 & Cell migration \\
\hline glutathione S-transferase theta 1-like & GSTT1L & -0.8721 & -1.6608 & $\begin{array}{l}\text { Glutathione } \\
\text { metabolic process }\end{array}$ \\
\hline 3-hydroxyacyl-CoA dehydratase 1 & HACD 1 & -0.6756 & - & $\begin{array}{lr}\begin{array}{l}\text { Biosynthesis of } \\
\text { unsaturated fatty }\end{array} & \end{array}$ \\
\hline
\end{tabular}




\begin{tabular}{|c|c|c|c|c|}
\hline 3-hydroxyacyl-CoA dehydratase 2 & HACD2 & -0.8972 & - & $\begin{array}{l}\text { Biosynthesis } \\
\text { unsaturated } \\
\text { acids }\end{array}$ \\
\hline hexosaminidase subunit beta & HEXB & 0.6435 & - & Lysosome \\
\hline hydroxysteroid 17-beta dehydrogenase 4 & HSD17B4 & - & -0.6621 & $\begin{array}{l}\text { Biosynthesis } \\
\text { unsaturated } \\
\text { acids }\end{array}$ \\
\hline hydroxysteroid 17-beta dehydrogenase 7 & HSD17B7 & -0.5881 & -2.4130 & $\begin{array}{l}\text { Cholesterol } \\
\text { biosynthetic process }\end{array}$ \\
\hline lysosomal protein transmembrane 5 & LAPTM5 & 0.9107 & - & Lysosome \\
\hline lymphocyte cytosolic protein 1 & LCP1 & 1.0106 & 1.3440 & Cell migration \\
\hline lipopolysaccharide induced TNF factor & LITAF & 1.4160 & - & Lysosome \\
\hline lipoprotein lipase & LPL & -0.9416 & -1.1173 & Fatty acids uptake \\
\hline microtubule associated protein 4 & MAP4 & -0.9481 & 0.7177 & ATP binding \\
\hline myosin IC & MYO1C & -0.8652 & -2.3751 & $\begin{array}{l}\text { Vesicle transport } \\
\text { along actin filament }\end{array}$ \\
\hline myosin ID & MYO1D & -1.1792 & -0.6408 & $\begin{array}{l}\text { Vesicle transport } \\
\text { along actin filament }\end{array}$ \\
\hline alpha-N-acetylgalactosaminidase & NAGA & - & 0.9444 & Lysosome \\
\hline nucleosome assembly protein 1 like 1 & NAP1L1 & -0.6481 & -0.9340 & Cell differentiation \\
\hline 3-oxoacyl-ACP synthase, mitochondrial & OXSM & -0.9256 & - & $\begin{array}{l}\text { Fatty acid } \\
\text { biosynthesis }\end{array}$ \\
\hline phospholipase $\mathrm{C}$, delta 1 & PLCD1 & -1.0615 & -0.7028 & $\begin{array}{l}\text { Inositol phosphate } \\
\text { biosynthesis }\end{array}$ \\
\hline perilipin 1 & PLIN1 & - & -1.8134 & $\begin{array}{l}\text { Lipid droplet } \\
\text { accumulation }\end{array}$ \\
\hline Perilipin 4 & PLIN4 & -2.0249 & -2.5699 & $\begin{array}{l}\text { Lipid droplet } \\
\text { accumulation }\end{array}$ \\
\hline cytochrome p450 oxidoreductase & POR & -1.5954 & -1.7337 & $\begin{array}{l}\text { Cholesterol } \\
\text { biosynthesis }\end{array}$ \\
\hline palmitoyl-protein thioesterase 1 & PPT1 & - & 1.1524 & Lysosome \\
\hline peroxiredoxin 6 & PRDX6 & -0.8673 & -1.0465 & $\begin{array}{l}\text { Oxidation-reduction } \\
\text { process }\end{array}$ \\
\hline polymerase I and transcript release factor & PTRF & -0.6130 & -1.1905 & $\begin{array}{l}\text { Positive regulation of } \\
\text { cell motility }\end{array}$ \\
\hline retinol saturase & RETSAT & -1.8673 & -4.2544 & $\begin{array}{l}\text { Oxidation-reduction } \\
\text { process }\end{array}$ \\
\hline raftlin, lipid raft linker 1 & RFTN1 & -1.3884 & -0.6067 & $\begin{array}{l}\text { Membrane } \quad \text { raft } \\
\text { assembly }\end{array}$ \\
\hline stearoyl-CoA desaturase (delta-9-desaturase) & SCD & -3.1763 & -0.9940 & $\begin{array}{l}\text { Fatty } \\
\text { biosynthesis }\end{array}$ \\
\hline solute carrier family 11 member 1 & SLC11A1 & 1.3671 & - & Lysosome \\
\hline solute carrier family 27 member 6 & SLC27A6 & -0.7859 & - & Fatty acids uptake \\
\hline sorbin and SH3 domain containing 1 & SORBS1 & -0.9871 & - & Lipid biosynthese \\
\hline vesicle amine transport 1 & VAT1 & -0.7330 & -0.9953 & $\begin{array}{l}\text { Oxidation-reduction } \\
\text { process }\end{array}$ \\
\hline vimentin & VIM & -0.8130 & -1.7467 & $\begin{array}{l}\text { Structural } \\
\text { constituent } \\
\text { cytoskeleton }\end{array}$ \\
\hline vanin 2 & VNN1 & 2.2386 & 1.4565 & Cell-cell adhesion \\
\hline
\end{tabular}

\section{Figures}


a

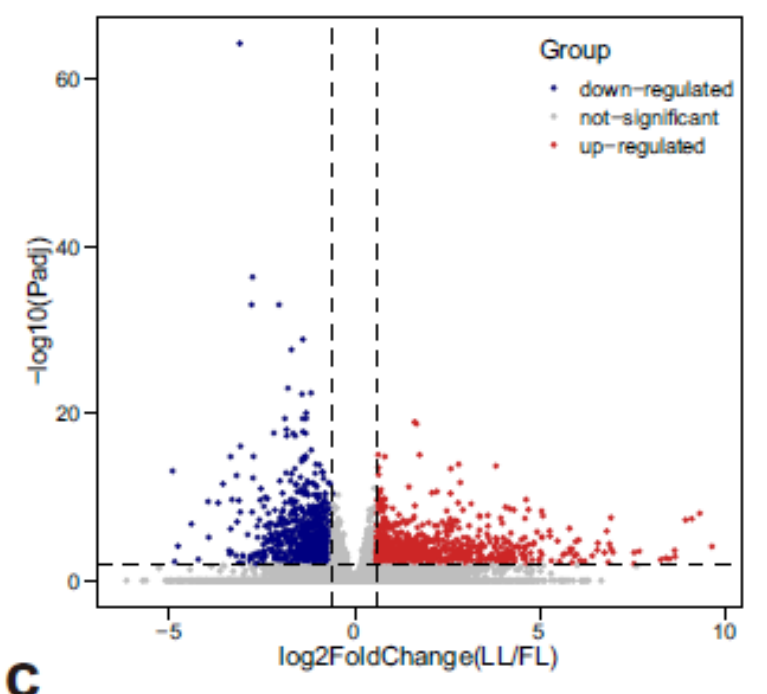

C

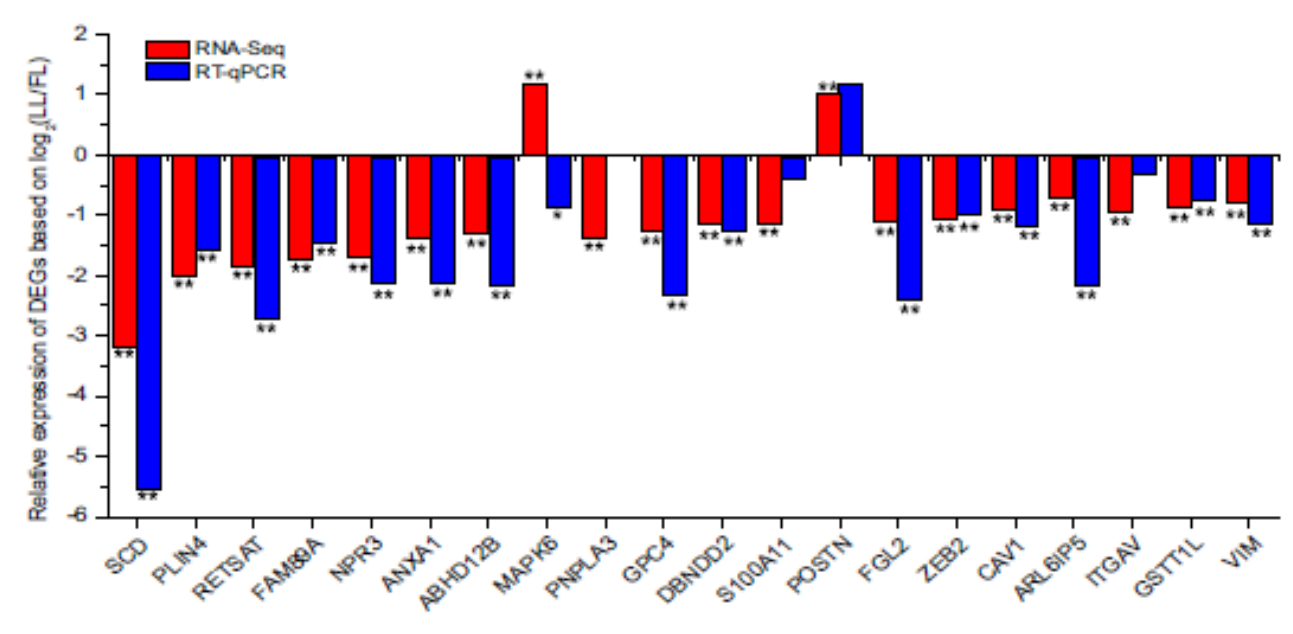

d

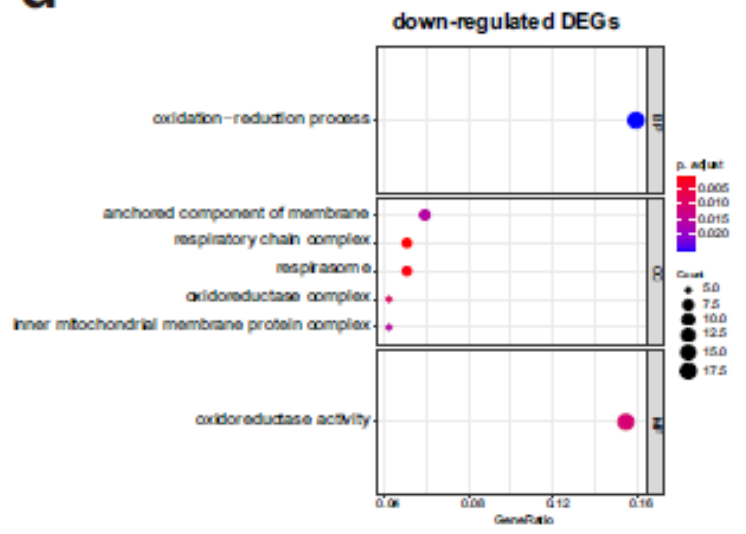

e

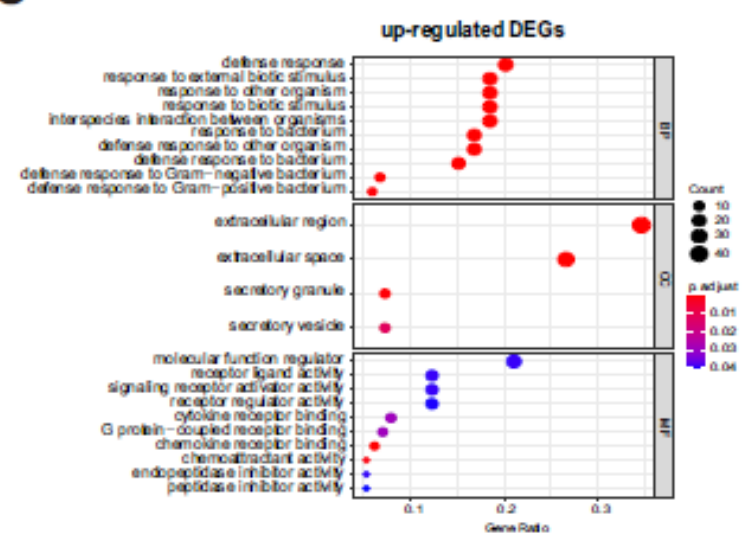

\section{Figure 1}

Transcriptome analysis. (a) Volcano plot of DEGs. X-axis shows log2(Fold Change), and Y-axis represents the - $\log 10$ (padj). (b) The heat map of hierarchical clustering of DEGs. LL and FL represent the lean and fat chicken lines, respectively. (c) Validation of DEGs by RT-qPCR ( $n=5$ for each line). * represents $p<$ 0.05 , ** represents $p<0.01$. (d) and (e) GO analysis of down- and up-regulated DEGs (corrected $p<0.05$ ). $\mathrm{X}$-axis, gene ratio, and $\mathrm{Y}$-axis, $\mathrm{GO}$ terms. 
a

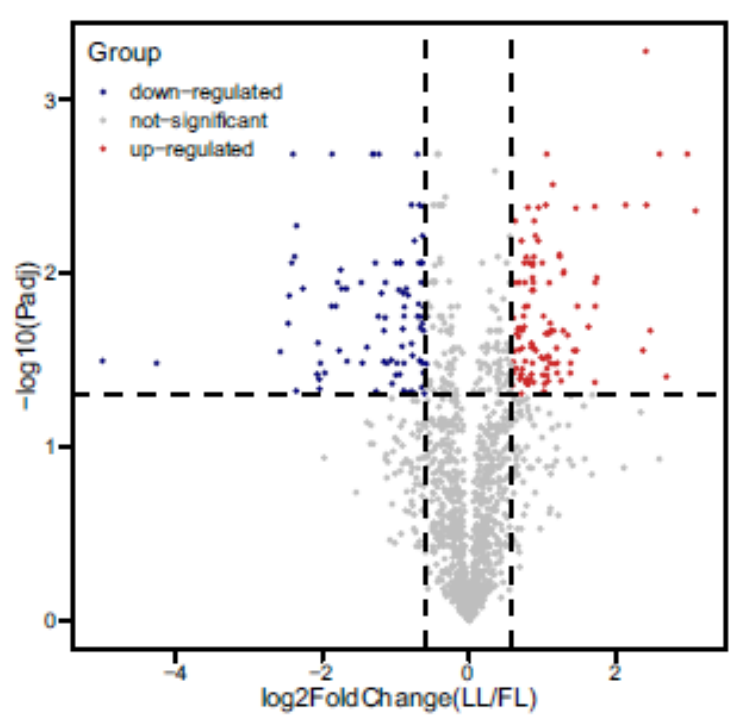

C

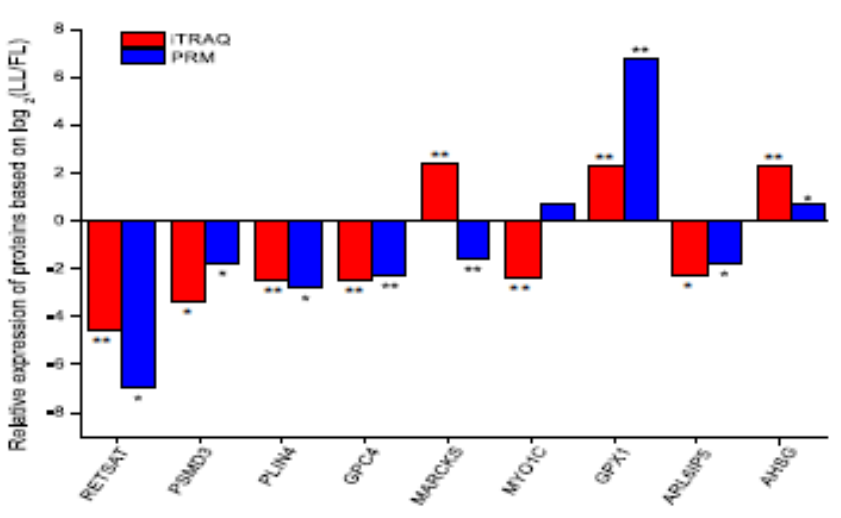

d

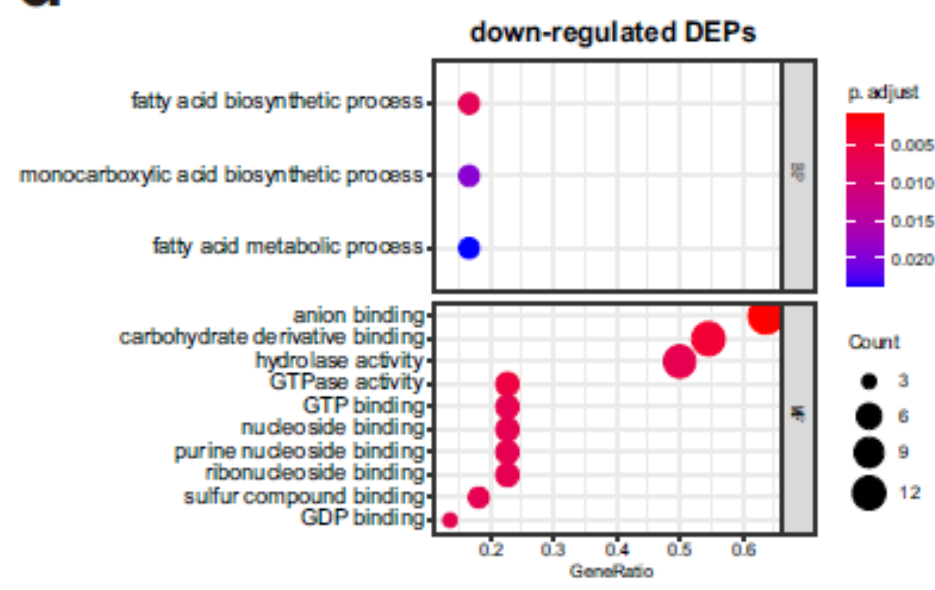

b

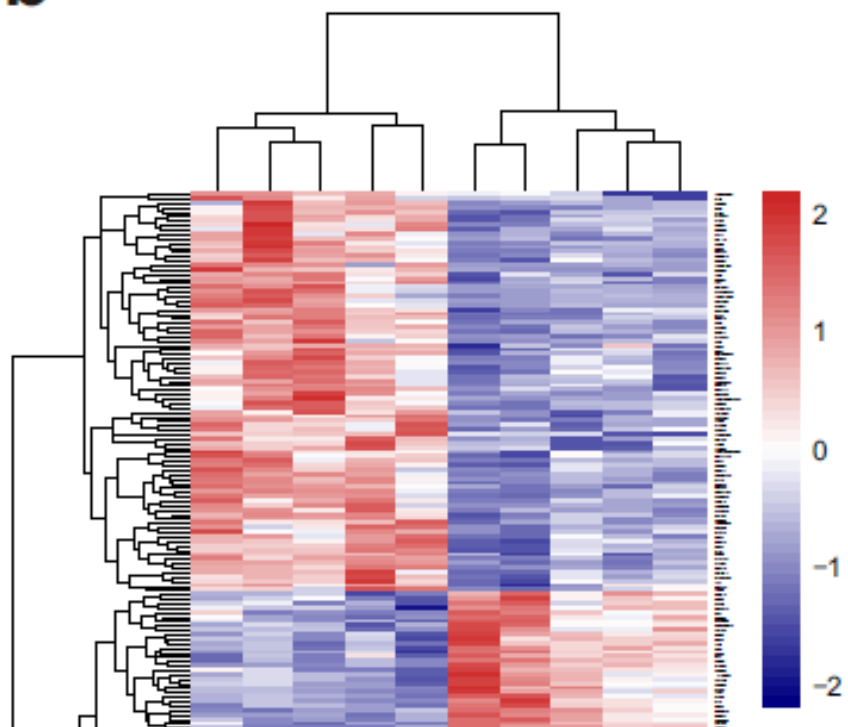

$\mathbf{e}$

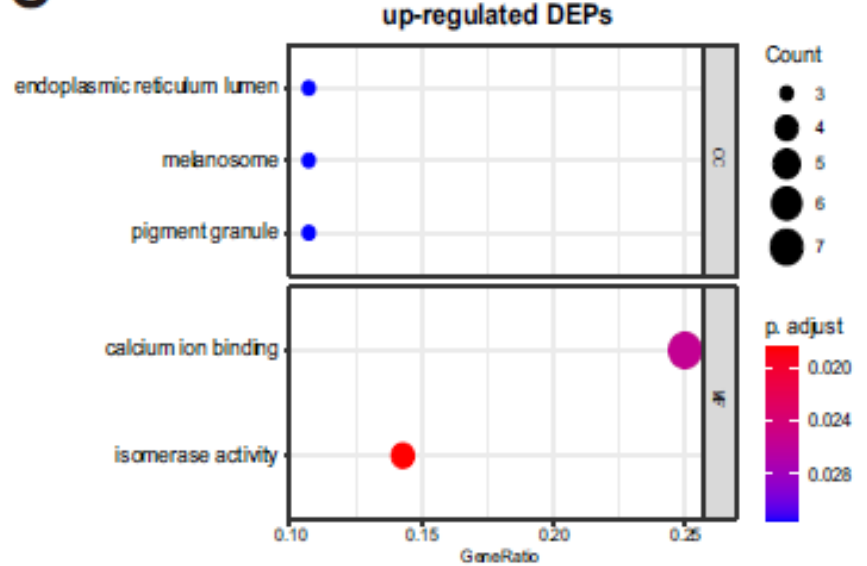

Figure 2

Proteome analysis. (a) Volcano plot of DEPs. X-axis, log2(Fold Change), and Y-axis, -log10(padj). (b) The heat map of hierarchical clustering of DEPs. LL and FL represent the lean and fat chicken lines, respectively. (c) Validation of DEPs by PRM analysis ( $n=3$ for each line). * represents $p<0.05$, ** represents $p<0.01$. (d) and (e) GO analysis of down- and up-regulated DEPs (corrected $p<0.05$ ). $X$-axis, gene ratio, and $\mathrm{Y}$-axis, $\mathrm{GO}$ terms. 
a

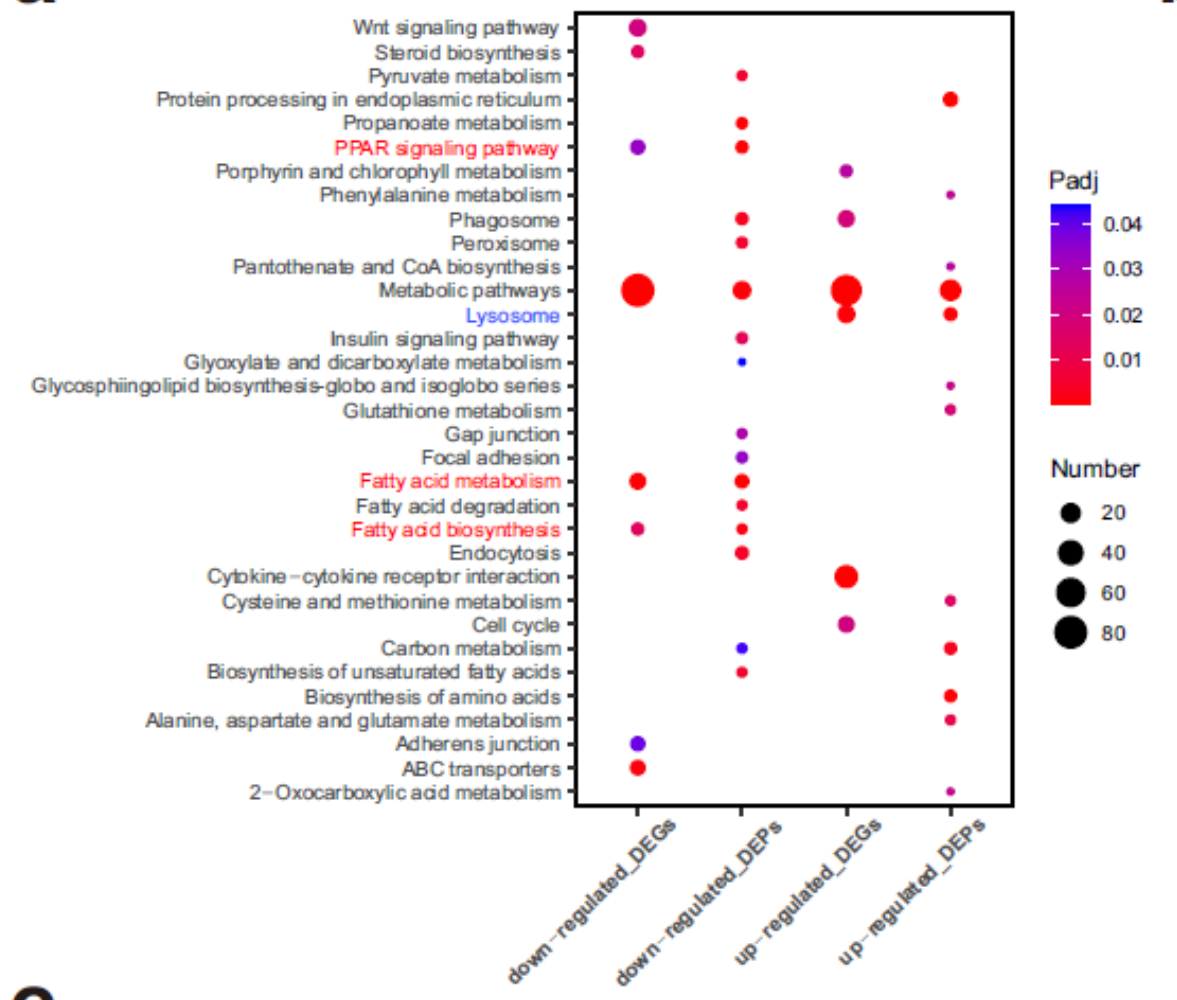

b
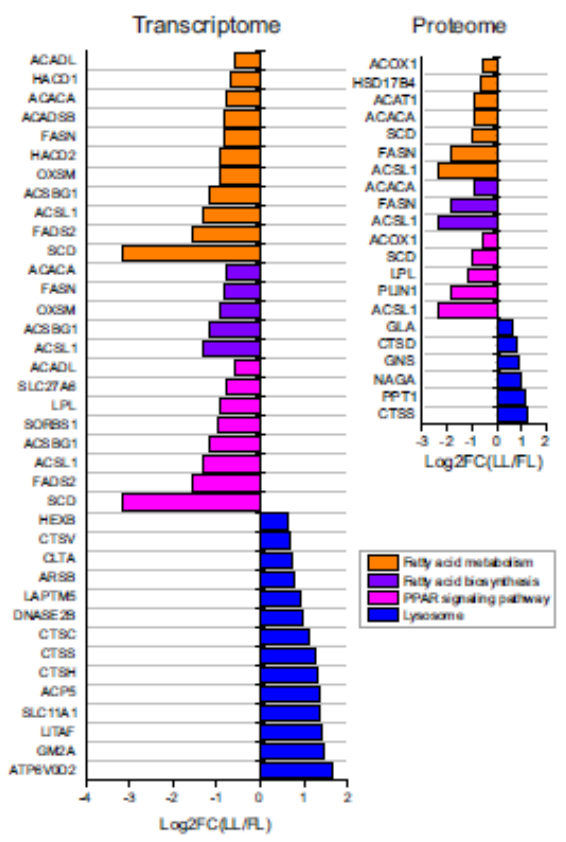

C

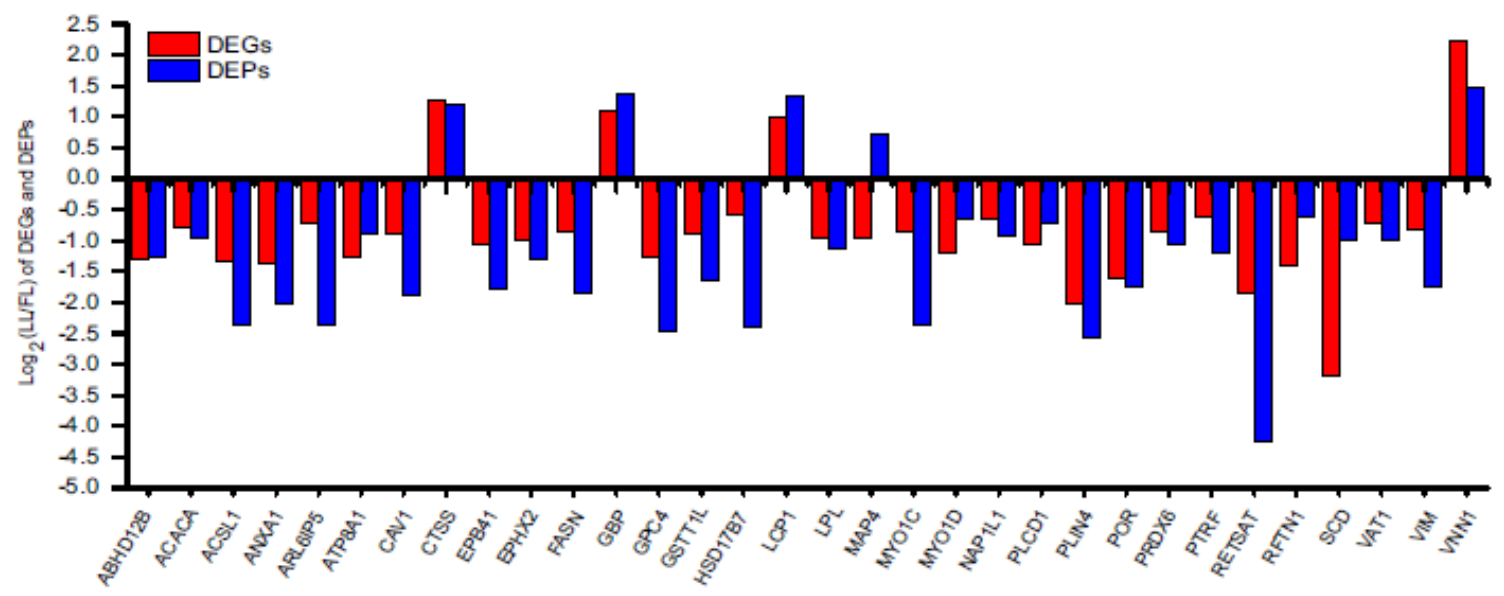

Figure 3

Integrated analysis of transcriptome and proteome. (a) The KEGG analysis of down- and up-regulated DEGs and DEPs (corrected $p<0.05$ ). The blue pathway represents overlapped pathways that enriched by both up-regulated DEGs and DEPs, and the red pathways represent overlapped pathways that enriched by both down-regulated DEGs and DEPs. (b) The expression levels of DEGs and DEPs in the four overlapped pathways that related to lipid metabolism. (c) The bar graph shows the expression trends of 32 shared genes at both the transcriptional and protein levels.

\section{Supplementary Files}


This is a list of supplementary files associated with this preprint. Click to download.

- NC3RsARRIVEGuidelinesChecklist2014.pdf

- Figures1.pdf

- Figures2.pdf

- TableS1.PrimersequencesusedforRTqPCR.docx

- TableS2.DEGsinabdominalfattissues.xIsx

- TableS3.DEPsinabdominalfattissues.xlsx 